\title{
ANALISIS SITUASI KESEHATAN MENTAL PADA MASYARAKAT DI INDONESIA DAN STRATEGI PENANGGULANGANNYA
}

\author{
Dumilah Ayuningtyas ${ }^{1}$, Misnaniarti, ${ }^{2}$ Marisa Rayhani ${ }^{1}$ \\ ${ }^{1}$ Fakultas Kesehatan Masyarakat, Universitas Indonesia, Depok \\ ${ }^{2}$ Fakultas Kesehatan Masyarakat, Universitas Sriwijaya, Palembang
ANALYSIS OF MENTAL HEALTH SITUATION ON COMMUNITY IN INDONESIA AND THE INTERVENTION STRATEGIES

\begin{abstract}
Background: Mental health is an important sector in realizing comprehensive health. There are about 450 million people suffer from mental and behavioural disorders worldwide, mostly in India (4.5\%). One person in four will suffer one or more of these disorders during their lifetime. Mental disorders if not dealt with properly, will get worse, and ultimately can burden the family, society, and government. Purpose of this study is to know the mental health situation in Indonesian society and its intervention strategies.

Methods: This paper used descriptive explorative analysis, through literature review and secondary data review. Unit of analysis is the mental health situation in Indonesia

Results: Based on the 2013 Riskesdas, prevalence of severe mental disorders in Indonesia's population is 1.7 per mil, higher in D.I. Yogyakarta, Aceh, South Sulawesi. The emotional mental disorder shown symptoms of depression and anxiety is about 6\%. Until now, there are still stigma and discrimination against people with mental disorders in Indonesia, so that experience incorrect handling and mistreatment such as restrain. Therefore, optimal strategy needed for every individual, family and society with promotive, preventive, curative and rehabilitative approach, integrated and sustainable. The mental health can be improved by effective public health interventions. Paradigm in the mental health movement that puts forward the prevention aspect as well as the role of community to help the optimization of individual mental function.

Conclusion: There are still many cases of mental health disorders in community, and mistreatment in Indonesia. Therefore, governance need to comprehensive effort for intervention, beginning with the policy regulation which is the basis for increasing funding and access to mental health services and supported by community-based approach.
\end{abstract}

Keywords: Depression, mental disorder, psychosocial, restrain, skizofrenia

\begin{abstract}
ABSTRAK
Latar Belakang: Kesehatan mental merupakan sektor penting dalam mewujudkan kesehatan secara menyeluruh. Terdapat sekitar 450 juta orang menderita gangguan mental dan perilaku di seluruh dunia, terbanyak di India $(4,5 \%)$. Satu dari empat orang menderita satu atau lebih gangguan mental selama masa hidup mereka. Gangguan mental jika tidak ditangani dengan tepat, akan bertambah parah, dan akhirnya dapat membebani keluarga, masyarakat, serta pemerintah. Studi ini bertujuan mengetahui situasi kesehatan mental pada masyarakat Indonesia dan strategi penanggulangannya.

Metode: Tulisan ini menggunakan analisis deskriptif eksploratif, melalui tinjauan literatur dan kajian data sekunder. Unit analisis yaitu situasi kesehatan mental di Indonesia.

Hasil Penelitian: Berdasarkan kajian data Riskesdas 2013 diketahui prevalensi gangguan mental berat pada penduduk Indonesia 1,7\%, terbanyak di Yogyakarta, Aceh, Sulawesi Selatan. Adapun gangguan mental emosional dengan gejala-gejala depresi dan kecemasan sekitar 6\%. Hingga saat ini, masih terdapat stigma dan diskriminasi terhadap orang dengan gangguan mental di Indonesia, sehingga mengalami penanganan serta perlakuan salah seperti pemasungan. Oleh karena itu strategi yang optimal perlu dilakukan bagi setiap individu, keluarga dan masyarakat dengan pendekatan promotif, preventif, kuratif, dan rehabilitatif secara menyeluruh, terpadu dan berkesinambungan. Kesehatan mental dapat ditingkatkan dengan intervensi kesehatan masyarakat yang efektif. Paradigma dalam gerakan kesehatan mental yang lebih mengedepankan pada aspek pencegahan serta peran komunitas untuk membantu optimalisasi fungsi mental individu.

Kesimpulan: Masih banyaknya kasus gangguan kesehatan mental pada masyarakat, dan penanganannya yang salah di Indonesia. Pemerintah perlu melakukan upaya penanggulangan yang menyeluruh, dimulai
\end{abstract}

Alamat Koresponding: Misnaniarti, Fakultas Kesehatan Masyarakat Universitas Sriwijaya. Jl. Palembang Prabumulih KM. 32, Indralaya Indah Kabupaten Ogan Ilir, Sumatera Selatan, email : misnaniarti@fkm.unsri.ac.id 
adanya peraturan kebijakan yang menjadi dasar dukungan pendanaan dan akses ke pelayanan kesehatan mental serta didukung pendekatan berbasis komunitas.

Kata kunci: Depresi, gangguan mental, psikososial, pemasungan, skizofrenia.

\section{PENDAHULUAN}

Kesehatan mental atau kesehatan jiwa merupakan aspek penting dalam mewujudkan kesehatan secara menyeluruh. Kesehatan mental juga penting diperhatikan selayaknya kesehatan fisik. There is no health without mental health, ${ }^{1}$ sebagaimana definisi sehat yang dikemukakan oleh World Health Organization (WHO) ${ }^{2}$ bahwa "health as a state of complete physical, mental and social well-being and not merely the absence of disease or infirmity."

Kesehatan mental merupakan komponen mendasar dari definisi kesehatan. Kesehatan mental yang baik memungkinkan orang untuk menyadari potensi mereka, mengatasi tekanan kehidupan yang normal, bekerja secara produktif, dan berkontribusi pada komunitas mereka. ${ }^{1}$

Oleh karena itu adanya gangguan kesehatan mental tidak bisa kita remehkan, karena jumlah kasusnya saat ini masih cukup mengkhawatirkan. Terdapat sekitar 450 juta orang menderita gangguan mental dan perilaku di seluruh dunia. Diperkirakan satu dari empat orang akan menderita gangguan mental selama masa hidup mereka. ${ }^{3}$ Menurut WHO regional Asia Pasifik (WHO SEARO) jumlah kasus gangguan depresi terbanyak di India (56.675.969 kasus atau $4,5 \%$ dari jumlah populasi), terendah di Maldives (12.739 kasus atau 3,7\% dari populasi). Adapun di Indonesia sebanyak 9.162.886 kasus atau 3,7\% dari populasi. ${ }^{4}$

Sistem kesehatan di dunia dianggap belum cukup menanggapi beban gangguan mental, sehingga terdapat kesenjangan antara kebutuhan akan perawatan dan persediaannya yang sangat besar. Sekitar $85 \%$ orang dengan gangguan mental parah di negara berkembang tidak mendapat pengobatan atas gangguannya. Sejalan dengan ini juga diketahui bahwa pengeluaran setahun bagi kesehatan mental masih rendah yaitu kurang dari US\$ 2 per orang, serta tenaga kesehatan mental yang kurang dari 1 per 100.000 populasi. ${ }^{1,5}$ Demikian juga di Indonesia, dengan berbagai faktor biologis, psikologis dan sosial dengan keanekaragaman penduduk, maka jumlah kasus gangguan jiwa kemungkinan akan terus bertambah. Oleh karena penting di setiap negara memiliki upaya penanggulangan akibat dari gangguan kesehatan mental ini.

Gangguan jiwa berat dapat menyebabkan turunnya produktivitas pasien dan akhirnya menimbulkan beban biaya besar yang dapat membebani keluarga, masyarakat, serta pemerintah. Lebih jauh lagi gangguan jiwa ini dapat berdampak pada penambahan beban negara dan penurunan produktivitas manusia untuk jangka panjang. Kondisi neuropsikiatrik menyumbang $13 \%$ dari total Disability Adjusted Life Years (DALYs) yang hilang karena semua penyakit dan cedera di dunia dan diperkirakan meningkat hingga $15 \%$ pada tahun 2020. Kasus depresi saja menyumbang $4,3 \%$ dari beban penyakit dan merupakan salah satu yang terbesar penyebab kecacatan di seluruh dunia, khususnya bagi perempuan. ${ }^{1,3}$

Kondisi mental yang sehat pada tiap individu tidaklah dapat disamaratakan. Kondisi inilah yang semakin membuat urgensi pembahasan kesehatan mental yang mengarah pada bagaimana memberdayakan individu, keluarga, maupun komunitas untuk mampu menemukan, menjaga, dan mengoptimalkan kondisi sehat mentalnya dalam menghadapi kehidupan sehari-hari. ${ }^{6}$

Tantangan lainnya adalah adanya stigma keliru tentang gangguan jiwa yang menghambat akses ke pelayanan kesehatan sehingga mengakibatkan penanganan yang salah. Seperti laporan Human Rights Watch Indonesia yang menyoroti buruknya penanganan di Indonesia terhadap warga yang 
mengalami gangguan kesehatan jiwa. Diketahui bahwa lebih dari 57.000 orang dengan disabilitas psikososial (kondisi kesehatan mental), setidaknya sekali dalam hidup mereka pernah dipasung. ${ }^{7}$ Oleh karena itu, tulisan ini bertujuan untuk mengetahui situasi kesehatan mental pada masyarakat di Indonesia dan strategi untuk penanggulangannya.

\section{METODE}

Tulisan ini merupakan analisis situasi menggunakan eksplorasi deskriptif yang dilakukan pada tahun 2017. Sumber informasi terdiri dari beberapa, diantaranya survey Riskesdas 2013, ${ }^{8}$ laporan-laporan hasil kegiatan WHO, ${ }^{1-5}$ penelitian-penelitian terdahulu tentang topik kesehatan mental, serta peraturan dan kebijakan yang terkait. Termasuk pula buku, jurnal, dan artikel terkait dari media elektronik menggunakan kata kunci "kesehatan mental di Indonesia", "gangguan kesehatan mental", serta "strategi kesehatan mental di Indonesia" yang menjadi subjek utama dari penelitian ini. Informasi yang diperoleh sebagai data dan temuan dikumpulkan, dikelola, kemudian ditinjau secara kritis. Unit analisis yaitu situasi kesehatan mental di Indonesia. Analisis dilakukan untuk mengkaji situasi dan strategi penanganan kesehatan mental di Indonesia.

\section{PEMBAHASAN}

\section{Konsep Kesehatan Mental}

Definisi kesehatan mental menurut WHO adalah kondisi kesejahteraan (wellbeing) seorang individu yang menyadari kemampuannya sendiri, dapat mengatasi tekanan kehidupan yang normal, dapat bekerja secara produktif dan mampu memberikan kontribusi kepada komunitasnya. ${ }^{1}$

Berdasarkan UU Nomor 18 Tahun 2014 tentang Kesehatan Jiwa, kesehatan jiwa didefinisikan sebagai kondisi dimana seorang individu dapat berkembang secara fisik, mental, spiritual, dan sosial sehingga individu tersebut menyadari kemampuan sendiri, dapat mengatasi tekanan, dapat bekerja secara produktif, dan mampu memberikan kontribusi untuk komunitasnya. ${ }^{9}$

Kesehatan mental jelas merupakan bagian integral dari definisi sehat sehingga tujuan dan tradisi kesehatan masyarakat dan promosi kesehatan dapat diterapkan sama bermanfaatnya dalam bidang kesehatan mental. Kesehatan mental membahas lebih daripada tidak adanya penyakit mental, yang sangat penting bagi individu, keluarga dan masyarakat. Kesehatan mental merupakan pendekatan multidisiplin yang mencakup promosi kesejahteraan, kesehatan mental dan pencegahan penyakit. ${ }^{10,11}$

\section{Klasifikasi Gangguan Kesehatan Mental}

Gangguan mental menurut WHO, terdiri dari berbagai masalah, dengan berbagai gejala. Namun, mereka umumnya dicirikan oleh beberapa kombinasi abnormal pada pikiran, emosi, perilaku dan hubungan dengan orang lain. Contohnya adalah skizofrenia, depresi, cacat intelektual dan gangguan karena penyalahgunaan narkoba, gangguan afektif bipolar, demensia, cacat intelektual dan gangguan perkembangan termasuk autisme. ${ }^{12}$

Pada konteks kesehatan jiwa, dikenal dua istilah untuk individu yang mengalami gangguan jiwa. Pertama, Orang dengan Masalah Kejiwaan (ODMK) merupakan orang yang memiliki masalah fisik, mental, sosial, pertumbuhan dan perkembangan, dan/atau kualitas hidup sehingga memiliki risiko mengalami gangguan jiwa. Kedua, Orang dengan Gangguan Jiwa (ODGJ) adalah orang yang mengalami gangguan dalam pikiran, perilaku, dan perasaan yang termanifestasi dalam bentuk sekumpulan gejala dan/ atau perubahan perilaku yang bermakna, serta dapat menimbulkan penderitaan dan hambatan dalam menjalankan fungsi orang sebagai manusia. ${ }^{9}$

Adapun kategori gangguan jiwa yang dinilai dalam data Riset Kesehatan Dasar 
(Riskedas) 2013 diketahui terdiri dari gangguan mental emosional (depresi dan kecemasan), dan gangguan jiwa berat (psikosis). ${ }^{8}$ Bentuk gangguan jiwa lainnya yaitu postpartum depression dan bunuh diri (suicide). ${ }^{13}$ Gangguan mental emosional atau distress psikologik merupakan keadaan yang mengindikasikan seseorang sedang mengalami perubahan psikologis. Gangguan ini berisiko menjadi lebih serius apabila tidak berhasil ditanggulangi.

Menurut The ICD-10 edisi tahun 2010, dan The ICD-10 Classification of Mental and Behavioural Disorders: clinical descriptions and diagnostic guidelines tahun 1992, gangguan mental dapat diklasifikasikan menjadi 11 kategori berikut: ${ }^{14,15}$

1. F00-F09: Organic, including symptomatic, mental disorders

2. F10-F19: Mental and behavioural disorders due to psychoactive substance use

3. F20-F29: Schizophrenia, schizotypal and delusional disorders

4. F30-F39: Mood [affective] disorders

5. F40-F48: Neurotic, stress-related and somatoform disorders

6. F50-F59: Behavioural syndromes associated with physiological disturbances and physical factors

7. F60-F69: Disorders of adult personality and behaviour

8. F70-F79: Mental retardation

9. F80-F89: Disorders of psychological development

10. F90-F98: Behavioural and emotional disorders with onset usually occurring in childhood and adolescence

11. F99-F99: Unspecified mental disorder

\section{Prevalensi Gangguan Kesehatan Mental di Indonesia}

Berdasarkan data Riskesdas 2013 diketahui prevalensi gangguan jiwa berat secara nasional sebesar $1,7 \%$ (per mil), atau sebanyak 1.728 orang. ${ }^{8}$ Kondisi ini menurun daripada data yang dilaporkan pada tahun 2007 sebesar $4,6 \%{ }^{16}$ Prevalensi psikosis atau skizofrenia tertinggi di Yogyakarta $(2,7 \%$ ), Aceh $(2,7 \%)$, dan Sulawesi Selatan (2,6\%), sedangkan yang terendah di Kalimantan Barat $(0,7 \%){ }^{8}$

Selanjutnya, prevalensi gangguan mental emosional yang ditunjukkan dengan gejala-gejala depresi dan kecemasan terdapat sekitar 6\% atau sebesar 37.728 orang dari subyek yang diteliti pada Riskesdas 2013. Provinsi dengan prevalensi gangguan mental emosional tertinggi adalah Sulawesi Tengah $(11,6 \%)$, Sulawesi Selatan $(9,3 \%)$, Jawa Barat (9,3\%), sedangkan prevalensi terendah di Provinsi Lampung sekitar $1,2 \%{ }^{8}$

Prevalensi gangguan mental emosional ini terlihat menurun dibandingkan data hasil Riskesdas 2007 yang sebesar 11,6\%. Penilaian kesehatan mental ini menggunakan alat ukur serta metode yang sama pada Riskesdas 2007 dan 2013, menggunakan Self Reporting Questionnaire (SRQ) yang terdiri dari 20 butir pertanyaan. Gangguan mental emosional dikategorikan menjadi 3 yaitu gangguan ringan, sedang dan berat. Terjadi penurunan persentase pada tahun 2013 dibanding tahun 2007 pada semua kategori, yaitu $8,2 \%$ menjadi $4,2 \%$ untuk gangguan ringan, $2,1 \%$ menjadi $1,1 \%$ untuk gangguan sedang, dan $1,3 \%$ menjadi $0,5 \%$ untuk gangguan berat. ${ }^{8,16,17}$

Terdapat assosiasi (hubungan) yang bermakna secara statistik antara disabilitas dan gangguan mental emosional responden. Hal ini dapat dipahami karena seseorang yang mengalami disabilitas fisik dan disabilitas sosial, akan dapat mempengaruhi kondisi kejiwaan mereka. Menurut Santrock seperti yang dikutip Wardhani, bahwa kondisi fisik dapat menyebabkan persoalan mental dan sebaliknya masalah/kesulitan mental dapat memperburuk gejala fisik. ${ }^{17}$

Berdasarkan analisis lanjut dari data Riskesdas 2007, diketahui responden yang menderita satu penyakit kronis berisiko 2,6 kali lebih besar untuk mengalami gangguan 
mental emosional, begitu juga yang menderita dua penyakit kronis berisiko 4,6 kali, yang menderita tiga penyakit kronis atau lebih berisiko 11 kali. $^{18}$ Dampak lebih lanjut, gangguan mental merupakan faktor risiko terjadinya usaha bunuh diri dengan adjusted OR sebesar 7,16 (95\% CI: 3,65-14,04). ${ }^{19}$

Hingga saat ini, orang dengan gangguan jiwa berat di Indonesia masih mengalami pemasungan serta perlakuan salah. Proporsi rumah tangga yang pernah memasung anggota keluarga dengan gangguan jiwa berat sebesar $14,3 \%$, terbanyak pada penduduk yang tinggal di pedesaan $(18,2 \%)$ serta pada kelompok kuintil indeks kepemilikan terbawah $(19,5 \%) .{ }^{8}$ Berdasarkan data pemerintah yang tersedia, sekitar 18.800 orang masih di pasung, padahal pemerintah sudah melarang pasung sejak tahun $1977 .^{7}$

Tindakan ini termasuk pelanggaran hak asasi manusia. Hal ini masih terjadi karena pengobatan dan akses ke pelayanan kesehatan jiwa belum memadai, seperti penelitian di Surabaya disebutkan bahwa keluarga mengalami hambatan ke pelayanan kesehatan mental. ${ }^{20}$ Sama juga dengan kondisi di Northwestern China, diperkirakan prevalensi gangguan mental adalah 21\%. Namun, tingkat penggunaan layanan kesehatan mental hanya sekitar $2,45 \%$ sampai $4,67 \%$. $^{21}$

Hal lain yang menyebabkan gangguan kesehatan mental adalah karena masih adanya stigma dan diskriminasi terhadap penderita gangguan mental. ${ }^{7}$ Begitu juga di India, stigma terjadi pada pasien depresi dan lebih tinggi pada kasus psikosis. ${ }^{22}$ Disebutkan bahwa tingkat stigma diri yang lebih tinggi menghasilkan tingkat kepatuhan yang lebih rendah terhadap pengobatan. ${ }^{23}$

\section{Upaya Penanganan Kesehatan Mental di Indonesia}

Temuan terhadap situasi kesehatan mental di Indonesia menunjukkan pencapaian dari upaya implementasi kebijakan. Pelaksanaan upaya kesehatan mental perlu melibatkan sektor yang lebih luas daripada sektor kesehatan. Seperti yang dikemukakan $\mathrm{WHO}^{10,11}$ bahwa kesehatan mental ditentukan oleh banyak faktor dan interaksi sosial, psikologis dan faktor biologis, serta ekonomi dan lingkungan, terkait dengan perilaku. Hal tersebut mengindikasikan bukan hal yang sederhana untuk mencapai situasi kesehatan jiwa yang diharapkan.

Konsep upaya kesehatan mental di Indonesia yaitu kegiatan untuk mewujudkan derajat kesehatan mental yang optimal bagi setiap individu, keluarga dan masyarakat dengan pendekatan promotif, preventif, kuratif, dan rehabilitatif yang diselenggarakan secara menyeluruh, terpadu dan berkesinambungan oleh pemerintah, pemerintah daerah, dan/atau masyarakat. Pelaksanaan upaya kesehatan jiwa berdasarkan asas keadilan, perikemanusiaan, manfaat, transparansi, akuntabilitas, komprehensif, perlindungan, serta non diskriminasi. $^{9}$

Upaya promotif kesehatan jiwa bertujuan untuk mempertahankan dan meningkatkan derajat kesehatan jiwa masyarakat, menghilangkan stigma, diskriminasi, pelanggaran hak asasi ODGJ, serta meningkatkan pemahaman, keterlibatan, dan penerimaan masyarakat terhadap kesehatan jiwa. ${ }^{9}$ Oleh karena itu penting untuk melaksanakan upaya promotif di lingkungan keluarga, lembaga pendidikan, tempat kerja, masyarakat, fasilitas pelayanan kesehatan, media massa, lembaga keagamaan dan tempat ibadah, serta lembaga pemasyarakatan dan rumah tahanan.

Upaya preventif kesehatan jiwa bertujuan untuk mencegah terjadinya masalah kejiwaan, mencegah timbul dan/atau kambuhnya gangguan jiwa, mengurangi faktor risiko akibat gangguan jiwa pada masyarakat secara umum atau perorangan, serta mencegah timbulnya dampak masalah psikososial yang dilaksanakan di lingkungan keluarga, lembaga dan masyarakat. ${ }^{9}$ 
Upaya kuratif dilaksanakan melalui kegiatan pemberian pelayanan kesehatan terhadap ODGJ yang mencakup proses diagnosis dan penatalaksanaan yang tepat sehingga ODGJ dapat berfungsi secara wajar di lingkungan keluarga, lembaga dan masyarakat. Tujuan upaya kuratif adalah untuk penyembuhan dan pemulihan, pengurangan penderitaan, pengendalian disabilitas, dan pengendalian gejala penyakit. Kegiatan penatalaksanaan kondisi kejiwaan pada ODGJ dilaksanakan di fasilitas pelayanan bidang kesehatan jiwa. ${ }^{9}$

Selanjutnya upaya rehabilitatif kesehatan jiwa bertujuan untuk mencegah dan mengendalikan disabilitas, memulihkan fungsi sosial, memulihkan fungsi okupasional, mempersiapkan dan mempersiapkan dan memberi kemampuan ODGJ agar mandiri di masyarakat. Upaya rehabilitatif ini meliputi rehabilitatif psikiatrik, psikososial, serta rehabilitatif sosial (dapat dilaksanakan dalam keluarga, masyarakat, dan panti sosial). ${ }^{9}$

Saat ini UU No. 18/2014 tentang Kesehatan Jiwa menjadi pedoman dalam penyelenggaraan kesehatan jiwa yang komprehensif. Penetapan pelayanan kesehatan jiwa dasar dan rujukan menjadi upaya kesehatan jiwa yang dilaksanakan dengan membangun sistem pelayanan kesehatan jiwa berjenjang dan komprehensif. Selain aspek pelayanan juga ditetapkan sumber daya dalam penyelenggaraan tersebut diantaranya sumber daya manusia, fasilitas pelayanan, perbekalan, teknologi dan produk teknologi, serta pendanaan. ${ }^{9}$

Undang-undang ini menjadi dasar kebijakan penanganan kesehatan mental di Indonesia yang fokus pada peningkatan derajat kesehatan jiwa masyarakat serta pencegahan gangguan jiwa bagi mereka yang rentan atau berisiko. Secara tegas dituliskan bahwa setiap orang dan/atau menyuruh orang lain dengan sengaja melakukan pemasungan, penelantaran, kekerasan atau tindakan lainnya yang melanggar hak asasi ODMK dan ODGJ harus dipidana. ${ }^{9}$
Saat ini, upaya kesehatan jiwa di Indonesia dikelola oleh Direktorat Pencegahan dan Pengendalian Masalah Kesehatan Jiwa dan NAPZA Kementerian Kesehatan. Visinya yaitu meningkatkan pelayanan kesehatan jiwa masyarakat yang optimal dan berkeadilan yang akan dicapai dalam kurun 2015-2019 dengan fokus utama pada kemandirian dan kemitraan masyarakat mewujudkan jiwa yang sehat, mutu, pemerataan dan keterjangkauan pelayanan, perhatian pada kelompok risti dan pelayanan di rumah, serta profesionalisme tenaga kesehatan jiwa. $^{24}$

Direktorat Keswa Kemenkes mencanangkan Program Indonesia Bebas Pasung. Program tersebut telah memiliki pencapaian. Sebelum program bebas pasung dijalankan, hingga tahun 2009, jumlah kasus ODGJ dipasung yang ditemukan berjumlah 213 orang dan 170 orang diantaranya dibebaskan dan mendapat pelayanan medik. Namun sejak 2010 hingga bulan Desember 2014, jumlah kasus ODGJ dipasung yang ditemukan menjadi 6.671 kasus dengan 5.937 kasus dibebaskan dan mendapat pengobatan medik. $^{24}$

Direktorat Keswa Kemenkes juga menangani gangguan penyalahgunaan NAPZA sebagaimana menurut $\mathrm{WHO}^{13}$ menyatakan gangguan penggunaan NAPZA merupakan penyakit otak kronis kambuhan yang dapat ditanggulangi dengan berbagai program pencegahan dan pemulihan. Gangguan ini dalam ICD- $10^{14}$ disebut sebagai gangguan mental dan perilaku akibat zat psikoaktif.

Penanganan dini bagi pengguna NAPZA diwujudkan dalam program Wajib Lapor. Program ini mendorong pecandu agar datang mencari pertolongan secara sukarela sehingga dapat menjalankan rehabilitasi sesuai hasil asesmen. Harapannya, program ini dapat meningkatkan kesadaran keluarga sehingga mampu sedini mungkin mengenali anggota keluarganya yang terlibat masalah 
penggunaan NAPZA dan membawanya kepada layanan terapi rehabilitasi. ${ }^{24}$

Kondisi pelayanan kesehatan mental di Indonesia yang dilaporkan pada tahun 2010 menggambarkan perkembangan selama lima tahun sebelumnya antara lain adanya Undangundang kesehatan mental, pengembangan kebijakan kesehatan mental, pengembangan program perawatan kesehatan mental komunitas, pembentukan kelompok pengguna, memasukkan kesehatan mental dalam kegiatan di puskesmas, dan dukungan politik yang baik. $^{10}$

Kebijakan yang diterapkan dalam bentuk aksi pada masyarakat tidak hanya dilakukan oleh pemerintah dalam bentuk program nasional. Beberapa komunitas memberi perhatian dan menunjukkan kepedulian terhadap penanganan kesehatan. Gerakan berbasis komunitas (misal Komunitas Peduli Skizofrenia Indonesia), ketersediaan psikolog di Puskesmas (D.I. Yogyakarta), kader kesehatan jiwa dan Desa Siaga Sehat Jiwa, pemanfaatan teknologi (misal aplikasi kesehatan jiwa di masyarakat oleh Dirkeswa Kemenkes RI dan Pijar Psikologi). ${ }^{24}$

\section{Strategi Penanggulangan Masalah Kesehatan Mental}

Saat ini telah terjadi pergeseran paradigma dalam gerakan kesehatan mental yang lebih mengedepankan pada aspek pencegahan gangguan mental serta bagaimana peran komunitas dalam membantu optimalisasi fungsi mental individu. ${ }^{6}$ Konsep dan pandangan terhadap kesehatan jiwa serta permasalahannya mempengaruhi penanganan mulai dari kebijakan hingga tindakan yang dilakukan. ${ }^{25}$

Kesehatan mental, seperti aspek kesehatan lainnya, dapat dipengaruhi oleh berbagai faktor sosioekonomi yang perlu ditangani melalui strategi komprehensif untuk promosi, pencegahan, pengobatan, dan pemulihan dalam pendekatan keseluruhan pemerintah. $^{1}$

WHO mencanangkan visi dari rencana aksi kesehatan mental 2013-2020 yaitu dunia dimana kesehatan mental dihargai, dipromosikan dan dilindungi, gangguan mental dicegah dan orang yang terkena gangguan ini dapat melakukan berbagai hak asasi manusia dan mendapat akses kualitas tinggi, kesehatan sesuai budaya dan pelayanan sosial pada waktu yang tepat untuk mendorong pemulihan, yang memungkinkan untuk mencapai kesehatan pada level tertinggi dan berpartisipasi sepenuhnya dalam masyarakat dan di tempat kerja, bebas dari stigmatisasi dan diskriminasi. ${ }^{1}$

Secara keseluruhan, tujuan (goal) rencana aksi kesehatan mental ini adalah untuk mempromosikan kesehatan mental, mencegah gangguan mental, menyediakan pelayanan, meningkatkan pemulihan, mempromosikan Hak Asasi Manusia dan menurunkan kematian, kesakitan, dan kecacatan pada orang dengan gangguan mental. Rencana aksi tersebut secara spesifik memiliki tujuan (objectives) berikut: ${ }^{1,5}$

Tujuan 1: Untuk memperkuat kepemimpinan dan tata kelola yang efektif untuk kesehatan mental

Tujuan 2: untuk memberikan layanan kesehatan mental dan sosial yang komprehensif, terpadu dan responsif dalam pengaturan berbasis komunitas

Tujuan 3: untuk menerapkan strategi untuk promosi dan pencegahan dalam kesehatan mental

Tujuan 4: untuk memperkuat sistem informasi, bukti dan penelitian untuk kesehatan mental.

Target global yang ditetapkan untuk setiap tujuan memberikan dasar bagi tindakan keseluruhan dan pencapaian yang terukur terhadap tujuan global. Rencana aksi bergantung pada enam prinsip dan pendekatan lintas sektoral berikut: ${ }^{1}$

1. Cakupan kesehatan universal (Universal Health Coverage): Tanpa memandang 
usia, jenis kelamin, status sosial ekonomi, ras, etnis atau orientasi seksual, dan mengikuti prinsip keadilan, orang dengan gangguan mental harus dapat mengakses, tanpa risiko memiskinkan diri mereka sendiri, layanan sosial dan kesehatan esensial yang memungkinkan mereka mencapai pemulihan dan standar kesehatan tertinggi yang dapat dicapai.

2. Hak asasi manusia (Human Rights) : Strategi kesehatan mental, tindakan dan intervensi untuk pengobatan, pencegahan dan promosi harus dilakukan sesuai dengan Konvensi Hak-hak Penyandang Disabilitas dan instrumen hak asasi manusia regional dan internasional lainnya.

3. Praktik berbasis bukti (Evidence-Based Practice): Strategi kesehatan mental dan intervensi untuk pengobatan, pencegahan, dan promosi harus dilakukan berdasarkan bukti ilmiah dan/atau praktik terbaik, dengan mempertimbangkan budaya.

4. Pendekatan perjalanan kehidupan (Life Course Approach): Kebijakan, rencana, dan layanan untuk kesehatan mental perlu mempertimbangkan kebutuhan kesehatan dan sosial di semua tahapan perjalanan hidup, termasuk masa bayi, masa kanakkanak, masa remaja, dewasa dan usia yang lebih tua.

5. Pendekatan multisektoral (Multisectoral Approach): Respons yang komprehensif dan terkoordinasi untuk kesehatan mental membutuhkan kemitraan dengan berbagai sektor publik seperti kesehatan, pendidikan, ketenagakerjaan, yudisial, perumahan, sosial dan sektor lain yang relevan termasuk sektor swasta.

6. Pemberdayaan orang dengan gangguan mental dan cacat psikososial: Orang dengan gangguan mental dan cacat psikososial harus diberdayakan dan dilibatkan dalam advokasi kesehatan mental, kebijakan, perencanaan, legislasi, penyediaan layanan, pemantauan, penelitian, dan evaluasi.

Setiap negara dituntut agar memiliki kepekaan dan memprioritaskan kesehatan mental. Advokasi dengan pemerintah diperlukan pada pendekatan pengembangan pelayanan kesehatan mental yang costeffective dan berdasarkan komunitas. Ada berbagai program dan kebijakan pencegahan berbasis bukti yang tersedia yang dapat diimplementasikan. Disebutkan bahwa pencegahan dapat cost-effective untuk menurunkan risiko gangguan kesehatan mental, dan menunjukkan hasil jangka panjang yang signifikan., ${ }^{3,10}$

Selain itu, perlu adanya peraturan kesehatan mental yang dapat meningkatkan akses melalui pendanaan layanan kesehatan mental yang setara dengan layanan kesehatan fisik, atau dengan menetapkan bahwa layanan perlu disediakan melalui pusat perawatan kesehatan primer (puskesmas) dan di rumah sakit umum. $^{26}$

\section{KESIMPULAN DAN SARAN}

Berdasarkan hasil kajian menunjukkan terdapat banyak gangguan mental di masyarakat di Indonesia, walaupun angka prevalensi terlihat cenderung menurun dari periode 2007-2013. Hingga saat ini, orang dengan gangguan jiwa berat di Indonesia masih mengalami penanganan serta perlakuan salah. Hal ini terjadi karena adanya stigma yang keliru, sehingga perlu intervensi pendekatan kesehatan masyarakat. Program pencegahan disebutkan lebih cost-effective untuk menurunkan risiko gangguan kesehatan mental, terutama untuk hasil jangka panjang. Rekomendasi bagi Pemerintah agar melakukan upaya penanggulangan yang menyeluruh, dimulai dengan adanya peraturan kebijakan yang menjadi dasar dukungan pendanaan dan akses ke pelayanan kesehatan mental serta didukung pendekatan berbasis komunitas. 


\section{DAFTAR PUSTAKA}

1. WHO. Mental Health Action Plan 2013 2020. Geneva: World Health Organization. 2013.

2. WHO. Basic Documents. 43rd Edition. Geneva: World Health Organization. 2001.

3. WHO. Prevention of Mental Disorders, Effective Intervention and Policy Options (Summary Report). Geneva: World Health Organization collaboration with the Prevention Research Centre of the Universities of Nijmegen and Maastricht. 2004.

4. WHO. Depression and Other Common Mental Disorders. Global Health Estimates. Geneva: World Health Organization. 2017.

5. WHO. Global Mental Health Atlas Country Profile 2014. Geneva: World Health Organization. 2014.

6. Dewi, Kartika Sari. Buku Ajar Kesehatan Mental. Semarang: Lembaga Pengembangan dan Penjaminan Mutu Pendidikan Universitas Diponegoro. 2012.

7. Human Rights Watch. Hidup di Neraka, kekerasan terhadap penyandang Disabiltas Psikososial di Indonesia. Human Rights Watch Organization. http://www.hrw.org. Jakarta. 2016.

8. Kementrian Kesehatan RI. Badan Penelitian dan Pengembangan Kesehatan. Laporan Riset Kesehatan Dasar 2013. Jakarta; Kementerian Kesehatan RI. 2013.

9. Undang-undang Nomor 18 Tahun 2014 tentang Kesehatan Jiwa. Jakarta. Republik Indonesia.

10. WHO. Strengthening Mental Health Systems through Community-based Approaches, Report of an Informal Consultation. New Delhi India: World Health Organization Regional Officer for South-East Asia. 2011.

11. WHO. Promoting mental health: concepts, emerging evidence, practice. Geneva: World Health Organization. 2004.
12. WHO. Factsheet on Mental Disorders. Geneva: World Health Organization. 2017.

http://www.who.int/mediacentre/factshee ts/fs396/en/

13. WHO. Global Mental Health 2015. Geneva: World Health Organization. 2015.

14. WHO. International Statistical Classification of Diseases and Related Health Problems, 10th Revision, edition 2010. Geneva: World Health Organization. 2010.

15. WHO. The ICD-10 Classification of Mental and Behavioural Disorders: clinical descriptions and diagnostic guidelines. Geneva: World Health Organization. 1992.

16. Kementrian Kesehatan RI. Badan Penelitian dan Pengembangan Kesehatan. Laporan Riset Kesehatan Dasar 2007. Jakarta; Kementerian Kesehatan RI. 2007.

17. Wardhani, Yurika Fauziah., Paramita, Astridya. Pelayanan Kesehatan Mental dalam Hubungannya dnegan Disabilitas dan Gaya hidup Masyarakat Indonesia (Analisis Lanjut Riskesas 2007 dan 2013). Buletin Penelitian Sistem Kesehatan. 2016:19(1):99-107.

18. Widakdo, Giri., Besral. Efek Penyakit Kronis terhadap Ganguan Mental Emosional. Jurnal kesehatan Masyarakat Nasional. 2013;7(7):309-316.

19. Liu B-P, Qin P, Liu Y-Y, Yuan L, Gu L$X$, Jia C-X. Mental disorders and suicide attempt in rural China. Psychiatry Research. 2018;261:190-6.

20. Tristiana RD, Yusuf A, Fitryasari R, Wahyuni SD, Nihayati HE. Perceived barriers on mental health services by the family of patients with mental illness. International Journal of Nursing Sciences. 2018;5(1):63-7.

21. Liu L, Chen X-1, Ni C-p, Yang P, Huang Y-q, Liu Z-r, et al. Survey on the use of mental health services and help-seeking behaviors in a community population in Northwestern China. Psychiatry Research. 2018;262:135-40. 
22. Dev A, Gupta S, Sharma KK, Chadda RK. Awareness of mental disorders among youth in Delhi. Current Medicine Research and Practice. 2017;7(3):84-9.

23. Carrara BS, Ventura CAA. Self-stigma, mentally ill persons and health services: An integrative review of literature. Archives of Psychiatric Nursing. 2018;32(2):317-24.

24. Direktorat Pencegahan dan Pengendalian Masalah Kesehatan Jiwa dan NAPZA.
Program Bebas Pasung. Dalam http://sehat-jiwa.kemkes.go.id. Diakses Oktober 2017. 2015.

25. Siswanto. Kesehatan Mental; Konsep, Cakupan, dan Perkembangan. Yogyakarta: Penerbit Andi. 2007.

26. WHO. Improving Health Systems and Services for Mental Health (Mental Health Policy and Service Guidance Package). Geneva: World Health Organization. 2009. 